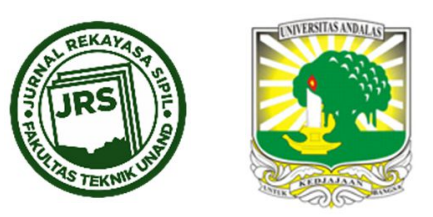

\title{
EVALUASI GEOMETRIK MEDIAN DAN KINERJA BUKAAN MEDIAN PADA JALAN BYPASS KOTA PADANG
}

\author{
TITI KURNIATI ${ }^{1}$, HENDRA GUNAWAN ${ }^{1}$, ALFI SAPUTRA $^{1}$ \\ ${ }^{1}$ Teknik Sipil, Fakultas Teknik, Universitas Andalas, Padang, Sumatera Barat, Indonesia \\ *Corresponding author: $\triangle$ titi@eng.unand.ac.id
}

Naskah diterima : 13 Juli 2021. Disetujui: 20 Desember 2021

\begin{abstract}
ABSTRAK
Jalan Padang By Pass menghubungkan dua gerbang utama Provinsi Sumatra Barat, yaitu Bandar Udara Internasional Minangkabau dan Pelabuhan Teluk Bayur. Sejak tahun 2018, tipe jalan ini menjadi empat lajur dua arah terbagi. Fasilitas pelengkap pada jalan terbagi adalah median dan bukaan median. Penempatan dan jarak antar bukaan median pada jalan Padang ByPass terindikasi tidak memenuhi persyaratan teknik sehingga dapat membahayakan pengguna jalan. Untuk itu perlu dilakukan evaluasi geometrik dan kinerja. Pengumpulan data primer dilakukan melalui survei lapangan, yaitu pengukuran geometrik median dan bukaan median serta perekaman data volume dan waktu tunggu kendaraan melakukan putar balik di bukaan median. Perekaman data volume lalu lintas dan waktu putar balik dengan perekaman video dilakukan untuk jam sibuk pagi (06.00-08.00), jam sibuk siang (12.00-14.00) dan jam sibuk sore (16.00-18.00) WIB. Pembacaan data dari video menggunakan aplikasi FILMORA9. Hasil survei geometrik ditampilkan secara deskriptif dan dievaluasi dengan membandingkan kondisi geometrik standar yang ditetapkan dalam SNI 2444/2008. Evaluasi kinerja bukaan median didasarkan pada waktu tunggu mengikuti Peraturan Menteri Perhubungan Republik Indonesia nomor 96 tahun 2015. Hasil evaluasi geometrik median jalan By Pass disimpulkan sesuai standar SNI 2444/2018. Ukuran panjang bukaan median dalam wilayah studi tidak memenuhi SNI 2444/2018 yaitu 12 meter. Panjang bukaan median eksisting di lapangan adalah 5-11 m. Jarak antar median pada sta 7+682, 8+041, 8+251, 8+602 yaitu 255, m, 335,1 m, 199,1 m, 125,5 m. Kondisi ini tidak memenuhi standar SNI 2444/2018 karena kurang dari $500 \mathrm{~m}$. Tiga bukaan median lainnya memenuhi syarat dengan jarak 565,4 m, $625 \mathrm{~m}$, dan $841 \mathrm{~m}$. Tingkat pelayanan $C$ terjadi pada bukaan median sta $7+682$ dan sta $8+602$, sedangkan lima stationing lainnya dengan tingkat pelayanan B. Pada sta 7+682 tingginya volume kendaraan yang putar balik dengan panjang bukaan median $8,5 \mathrm{~m}$ terjadi waktu tunggu di antrian 16 detik/kendaraaan. Pada sta $8+602$ panjang bukaan median hanya $5 \mathrm{~m}$, cukup sulit bagi kendaraan ringan untuk melakukan manuver putar balik pada lokasi tersebut. Waktu tunggu di antrian 23 detik/kendraan dan panjang antrian $1081 \mathrm{~m}$. Tingkat pelayanan C harus ditingkatkan menjadi B sesuai PerMenHub RI no.96/2015, yaitu dengan dengan menambah panjang bukaan median pada stasioning tersebut dan jika tidak memungkinkan bukaan median sebaiknya ditutup.
\end{abstract}

Kata kunci : median, bukaan median, putar balik, waktu tunggu, tingkat pelayanan 


\section{PENDAHULUAN}

Median jalan sebagai salah satu kelengkapan badan jalan sangat penting untuk memisahkan arus lalu lintas yang berlawanan arah yang dapat meningkatkan keamanan dan kelancaran lalu lintas. merupakan bagian tengah badan jalan yang secara fisik memisahkan arus lalu lintas yang berlawanan arah. Median jalan dapat berbentuk median yang ditinggikan, median yang diturunkan, atau median rata (Departemen Permukiman dan Prasarana Wilayah, 2004).

Bukaan median adalah fasilitas mengakomodasi kendaraan agar dapat melakukan gerakan putar balik pada tipe jalan terbagi dan dapat mengakomodasi gerakan memotong dan belok kanan (Departemen Pekerjaan Umum, 2008).

Jalan Padang By Pass sepanjang 27 kilometer menghubungkan dua gerbang utama Provinsi Sumatra Barat, yaitu Bandar Udara Internasional Minangkabau dan Pelabuhan Teluk Bayur. Jalan ini dibangun pada tahun 1993 dan dan seiring dengan pindahnya Balai kota Padang pada tahun 2013 ke kawasan jalan ini mengakibatkan meningkatnya arus lalu lintas. Dilakukan peningkatan kapasitas jalan ini dengan menambah jalur jalan yang ada dari satu jalur dua lajur tak terbagi menjadi dua jalur empat lajur terbagi. Pembangunannya dimulai sejak April 2014 dan mulai beroperasi awal tahun 2018.

Jalan By Pass Padang mempunyai tipe jalan 4 lajur 2 arah terbagi (4/2 D), fungsi jalan arteri dengan jenis perkerasan adalah perkerasan lentur. Sesuai dengan tipe jalan terbagi, terdapat median untuk memisahkan arus lalu lintas yang berlawanan arah dan bukaan median sebagai fasilitas kendaraan untuk memutar menuju arus sebaliknya.

Dari hasil pengamatan penempatan dan jarak antar bukaan median pada jalan Padang ByPass ini terindikasi tidak memenuhi persyaratan geometrik atau teknik sehingga dapat menyebabkan tundaan dan panjang antrian yang besar serta membahayakan pengguna pada panjang bukaan median yang terlalu kecil ukurannya. Karenanya perlu dilakukan evaluasi median dan bukaan median ditinjau dari aspek geometrik dan kinerja.

Ketika kendaraan hendak melakukan putar balik sering harus menunggu untuk tersedianya gap yang aman pada arus lawan. Hasil penelitian Sinaga dan Surbakti (2017) nilai gap kritis berdasarkan metode rata-rata adalah 8,806 detik pagi hari, 8,368 detik siang, dan 9,385 detik malam. Dengan metode Siegloch diperoleh hasil 7,525 detik di pagi, 7,2 detik di siang, dan 8,89 detik malam. Nilai tingkat pelayanan berdasarkan nilai derajat kejenuhan dengan metode rata-rata diperoleh ada pada tingkat bad hingga very bad, sedangkan dengan metode siegloch diperoleh nilai tingkat pelayanan good hingga tolerable (Sinaga \& Surbakti, 2017).

Metode Gap Acceptance untuk mendapatkan nilai gap, panjang antrian, gap dan waktu tunggu gap pada bukaan median berdasarkan penelitian Gultom, dkk (2019) adalah 439 kendaraan dan antrian akibat gap sebanyak 899 kendaraan, waktu tunggu gap yang terjadi sebanyak 309 kendaraan dan antrian akibat waktu tunggu sebanyak 1449 kendaraan.

Hasil evaluasi ditinjau dari geometrik bukaan median dan derajat kejenuhan ruas jalan pada beberapa ruas jalan di Kota Palu merekomendasikan geometrik median yang sesuai standar dan beberapa bukaan median ditutup (Barnabas et al., 2017).

Penelitian yang dilakukan Ramadhona dan Fauzi (2018) mengenai dampak gang pada putaran balik terhadap kinerja ruas jalan Affandi Yogyakarta pada kondisi eksisting menunjukkan nilai panjang antrian dan tundaan masing-masing sebesar 67,03 $\mathrm{m}$ dan 22,61s. Alternatif I menunjukkan bahwa pemindahan dan penutupan bukaan median fasilitas putar 
balik sejauh 60 meter dari gang didapatkan penurunan panjang antrian dan tundaan berturut-turut sebesar $91,84 \%$ dan $79,08 \%$. Usulan alternatif II menunjukkan bahwa pemindahan bukaan median sejauh 50 meter dari gang didapatkan penurunan panjang antrian dan tundaan sebesar $53,66 \%$ dan $76,64 \%$.

\section{METODA PENELITIAN}

Jalan By Pass Padang mempunyai tipe jalan 4 lajur 2 arah terbagi (4/2 D) dengan panjang $27 \mathrm{~km}$ terbentang dari arah Selatan ke Utara kota Padang. Terdapat tujuh bukaan median yang dievaluasi dalam wilayah wilayah studi (sta. $7+450$ sampai sta. 12+250) yang masingmasing yang berada di sta. $7+682$, sta. $8+041$, sta $8+251$, sta $8+602$, sta $9+171$, sta $10+071$ dan sta 10+912, seperti ditampilkan pada Gambar 1 .

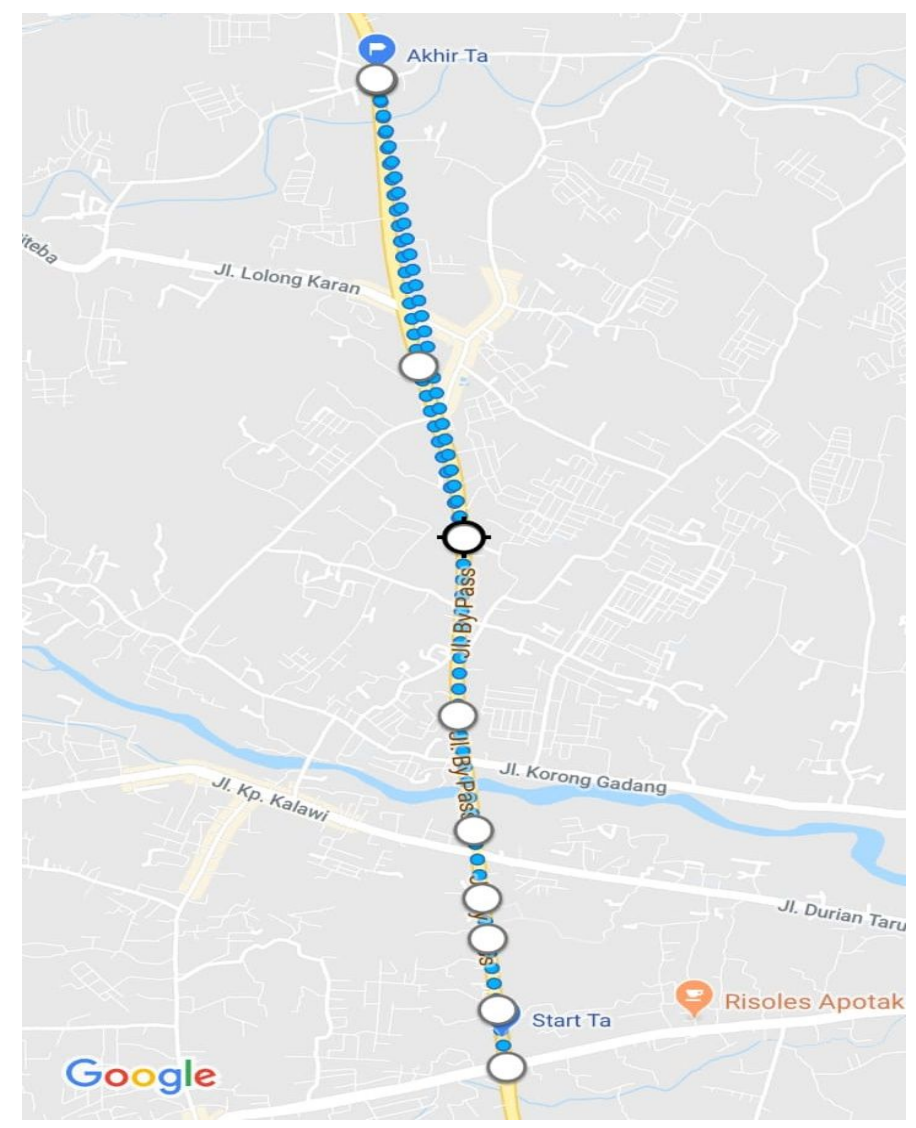

Gambar 1. Peta lokasi penelitian

Pengumpulan data primer dilakukan melalui survei lapangan, yaitu pengukuran geometrik median dan bukaan median serta perekaman data volume dan waktu kendaraan melakukan putar balik di bukaan median. Pengukuran geometrik median meliputi lebar dan tinggi median, sedangkan untuk bukaan median meliputi panjang, pelebaran dan jarak antar bukaan median dengan menggunakan meteran. Serta dilakukan juga pendokumentasian median dan bukaan median. Perekaman data volume dan waktu putar balik dengan perekaman video dilakukan untuk jam sibuk pagi (06.00-08.00), jam sibuk siang (12.0014.00) dan jam sibuk sore (16.00-18.00) WIB. Survei lapangan dilaksanakan tanggal 17 November 2018 sampai dengan 23 November 2018. 
Hasil survei geometrik ditampilkan secara deskriptif dan dievaluasi dengan membandingkan kondisi geometrik standar yang ditetapkan dalam SNI 2444:2008 Tentang Spesifikasi Bukaan Pemisah Jalur (Departemen Pekerjaan Umum, 2008)

Pembacaan data dari video menggunakan aplikasi FILMORA9, seperti terlihat pada Gambar 2. Hasilnya adalah volume dan waktu tunggu kendaraan saat putar balik pada bukaan median yang direkapitulasi dalam aplikasi Microsoft Excel. Data volume dan waktu tunggu merupakan data masukan untuk menentukan panjang antrian di bukaan median. Penentuan panjang antrian mengacu pada Pedoman Perencanaan Putaran Balik No. 06/BM/2005 (Direktorat Jenderal Bina Marga, 2005). Panjang antrian di lajur tepi pada jalur kendaraan sebelum melakukan gerakan putaran balik untuk tipe jalan 4 lajur 2 arah terbagi (4/2D) dihitung dengan menggunakan persamaan (1).

$$
\text { PanjangAntrian }=-1,29706+0,09778 * \text { waktutunggu }+0,00214 * \text { Vol } a_{1}
$$

Keterangan untuk persamaan (1) adalah waktu tunggu dalam detik dan volume a1 dalam $\mathrm{smp} / \mathrm{jam}$. Vol a1 = volume lajur paling dalam pada jalur searah dengan kendaraan yang akan memutar.

Data volume kendaraan dikonversi ke dalam satuan mobil penumpang ( $\mathrm{smp} / \mathrm{jam}$ ) menggunakan ekivalensi mobil penumpang mengikuti Manual Kapasitas Jalan Perkotaan (MKJI) 1997 untuk simpang tak bersinyal yaitu kendaraan ringan (LV):1,0; kendaraan berat (HV):1,3; sepeda motor (MC):0,5 (Direktorat Jenderal Bina Marga, 1997).

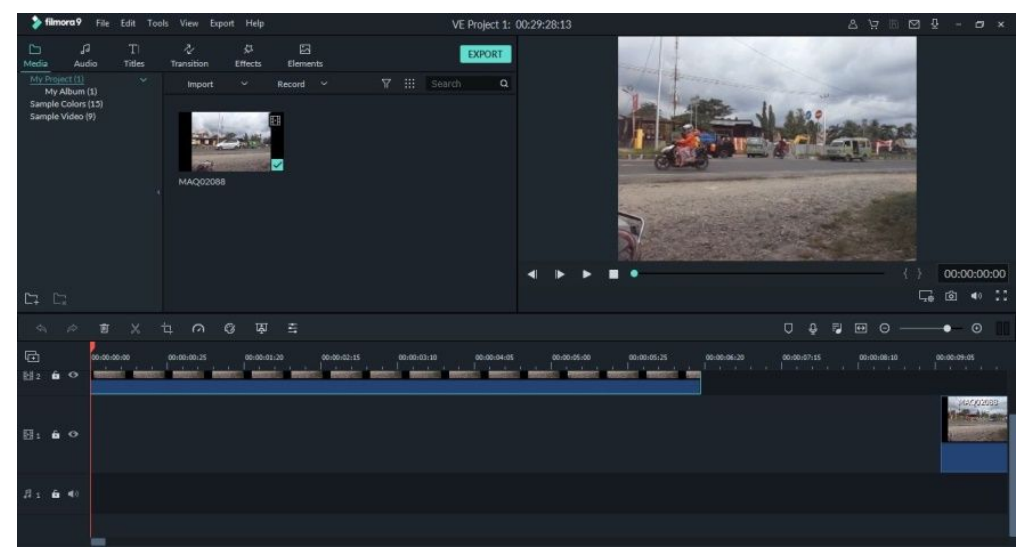

Gambar 2. Pembacaan data pada aplikasi FILMORA9

Evaluasi kinerja bukaan median didasarkan pada waktu tunggu mengikuti Peraturan Menteri Perhubungan Republik Indonesia nomor 96 tahun 2015 (Menteri Perhubungan RI, 2015):

Tabel 1. Tingkat Pelayanan Pada Persimpangan

\begin{tabular}{ll}
$\begin{array}{c}\text { Waktu tundaan } \\
\text { (detik/kendaraan) }\end{array}$ & $\begin{array}{l}\text { Tingkat } \\
\text { Pelayanan }\end{array}$ \\
\hline Tundaan $<5$ & $\mathrm{~A}$ \\
\hline $5 \leq$ tundaan $<15$ & $\mathrm{~B}$ \\
\hline $15 \leq$ tundaan $<25$ & $\mathrm{C}$ \\
\hline $25 \leq$ tundaan $<40$ & $\mathrm{D}$ \\
\hline $40 \leq$ tundaan $<40$ & $\mathrm{E}$ \\
\hline tundaan $\geq 60$ & $\mathrm{~F}$ \\
\hline
\end{tabular}




\section{HASIL DAN PEMBAHASAN}

\subsection{Evaluasi Median}

Penampang melintang jalan By Pass seperti ditunjukkan pada Gambar 3. mempunyai lebar jalur lalu lintas sebesar 8,3 meter untuk masing-masing arah dan dilengkapi dengan bahu jalan selebar 2 meter. Layout dan foto median jalan ditampilkan pada Gambar 4 dan Gambar 5.

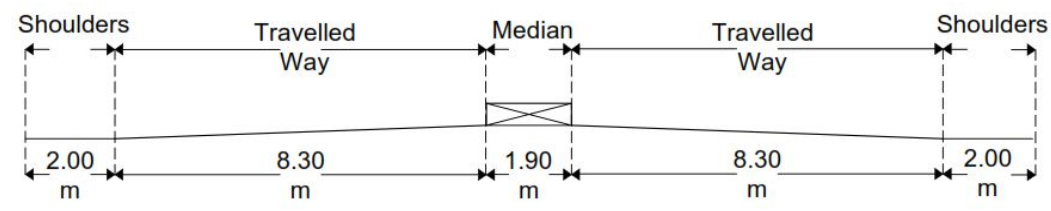

Gambar 3. Penampang melintang jalan By Pass

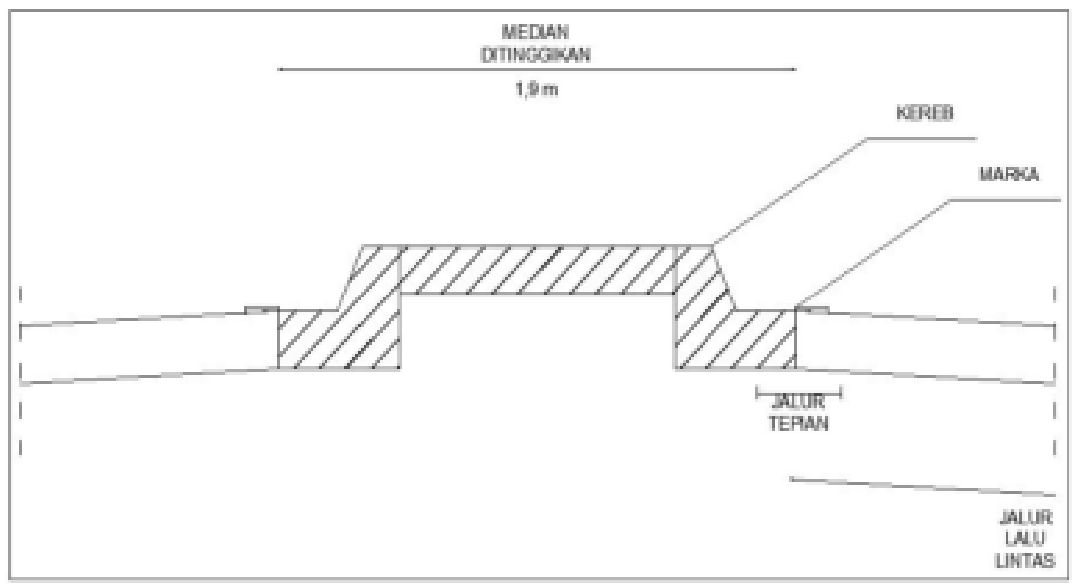

Gambar 4. Layout median jalan By Pass

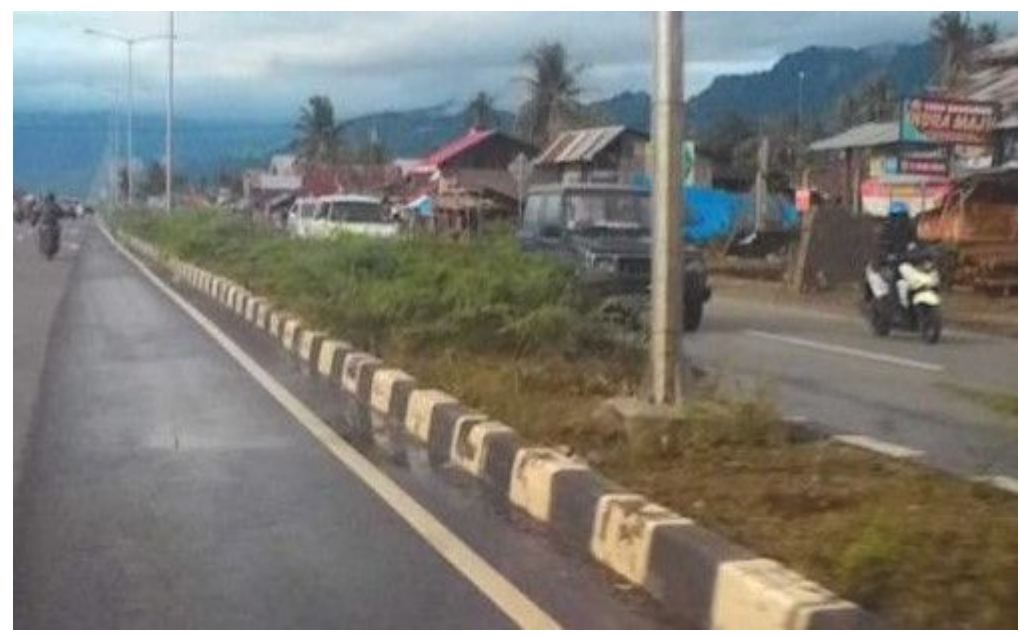

Gambar 5. Median jalan By Pass 
Evaluasi kesesuaian geometrik median jalan By Pass seperti ditampilkan pada Tabel 2. Berdasarkan evaluasi disimpulkan bahwa geometrik median sesuai dengan standar SNI 2444/2008 (Departemen Pekerjaan Umum, 2008), walaupun tinggi median kurang hanya $1 \mathrm{~cm}$. Hal ini dikarenakan lapis ulang (overlay) pada bagian perkerasan jalan.

Tabel 2. Evaluasi geometrik median

\begin{tabular}{llll}
\hline Kriteria & Eksisting & \multicolumn{1}{c}{$\begin{array}{c}\text { Standar SNI } \\
\mathbf{2 4 4 4 : 2 0 1 8}\end{array}$} & \multicolumn{1}{c}{ Keterangan } \\
\hline Fungsi jalan & Arteri & Arteri & Sesuai \\
\hline Lebar median & $1,9 \mathrm{~m}$ & $1,6 \mathrm{~m}$ & Sesuai \\
\hline Tipe median & Ditinggikan & Ditinggikan & Sesuai \\
\hline Tinggi median & $0,17 \mathrm{~m}$ & $0,18-0,25 \mathrm{~m}$ & Tidak sesuai \\
\hline Sisi luar dipasang kereb & Ada & Ada & Sesuai \\
\hline
\end{tabular}

\subsection{Evaluasi Bukaan Median}

Evaluasi bukaan median meliputi evaluasi geometrik dan evaluasi kinerja yang dinyatakan dalam tingkat pelayanan. Evaluasi geometrik bukaan median yaitu panjang bukaan, jarak antar bukaan (jarak sebelum bukaan dan sesudah stationing yang ditinjau) serta keberadaan pelebaran bukaan median, seperti pada Tabel 3.

Tabel 3. Evaluasi geometrik bukaan median

\begin{tabular}{|c|c|c|c|c|c|c|c|c|}
\hline \multirow{2}{*}{ Sta } & \multicolumn{2}{|c|}{$\begin{array}{c}\text { Panjang bukaan } \\
(\mathrm{m})\end{array}$} & \multicolumn{2}{|c|}{$\begin{array}{c}\text { Jarak dengan } \\
\text { bukaan sebelum } \\
(\mathrm{m})\end{array}$} & \multicolumn{2}{|c|}{$\begin{array}{c}\text { Jarak dengan } \\
\text { bukaan setelah (m) }\end{array}$} & \multicolumn{2}{|c|}{ Pelebaran } \\
\hline & eksisting & $\begin{array}{l}\text { SNI } \\
2444\end{array}$ & eksisting & $\begin{array}{l}\text { SNI } \\
2444\end{array}$ & eksisting & $\begin{array}{l}\text { SNI } \\
2444\end{array}$ & eksisting & $\begin{array}{l}\text { SNI } \\
2444\end{array}$ \\
\hline $7+682$ & 8,5 & 12 & 255,6 & 500 & 335,1 & 500 & Tidak ada & ada \\
\hline $8+041$ & 11,0 & 12 & 335,1 & 500 & 199,1 & 500 & Tidak ada & ada \\
\hline $8+251$ & 7,5 & 12 & 199,1 & 500 & 168,3 & 500 & Tidak ada & ada \\
\hline $8+602$ & 5,0 & 12 & 125,5 & 500 & 565,4 & 500 & Tidak ada & ada \\
\hline $9+171$ & 11,0 & 12 & 565,4 & 500 & 248,0 & 500 & Tidak ada & ada \\
\hline $10+071$ & 9,0 & 12 & 625,0 & 500 & 841,0 & 500 & Tidak ada & ada \\
\hline $10+912$ & 7,5 & 12 & 841,0 & 500 & 185,0 & 500 & Tidak ada & ada \\
\hline
\end{tabular}

Ditinjau dari panjang bukaan median, semua bukaan median dalam wilayah studi tidak memenuhi standar SNI 2444/2018. Pada sta 8+602 panjang bukaan median hanya $5 \mathrm{~m}$. Hal ini akan sangat sulit bagi kendaraan ringan untuk melakukan manuver putar balik pada lokasi tersebut, apalagi kendaraan berat tidak akan bisa melewatinya. Kalaupun bisa akan berakibat tundaan yang besar bagi lalu lintas searah lajur.

Jarak antar median pada sta 7+682, 8+041, 8+251, 8+602 tidak memenuhi standar SNI 2444 , tetapi pada sta $9+171,10+071$ dan 10+912 sudah memenuhi standar SNI. Ketiadaan pelebaran pada bukaan median akan menambah waktu manuver bagi kendaraan yang putar balik. Pada sta $8+602$ jarak bukaan dengan bukaan median sebelum sangat dekat yaitu 125,5 meter. Panjang antrian pada lokasi ini lebih besar dari jarak antar bukaan median. Antrian putar balik mengganggu kelancaran arus lalu lintas.

Gambar beberapa bukaan median dalam wilayah studi seperti terlihat pada Gambar 6 dan Gambar 7. Gambar 6 menampilkan bukaan median sta 8+041 dengan panjang bukaan median $11 \mathrm{~m}$ yang hampir memenuhi standar SNI 2444 yaitu $12 \mathrm{~m}$ dan bukaan median sta 8+602 yang sangat kecil panjang bukaan mediannya yaitu $5 \mathrm{~m}$. Gambar 7 merupakan gambar untuk bukaan median sta 9+171 dan sta 10+071. Ditinjau dari jarak antara bukaan sebelum dan sesudah kedua bukaan median ini memeuhi standar SNI 2444. 

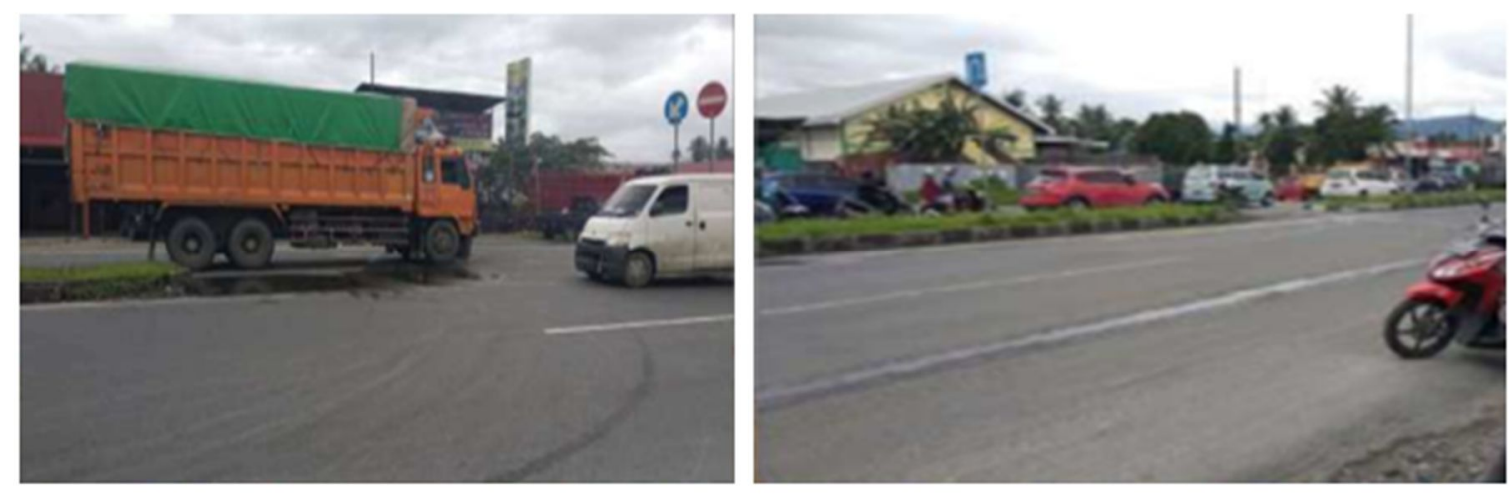

Gambar 6. Bukaan Median Sta 8+041 dan Sta 8+602
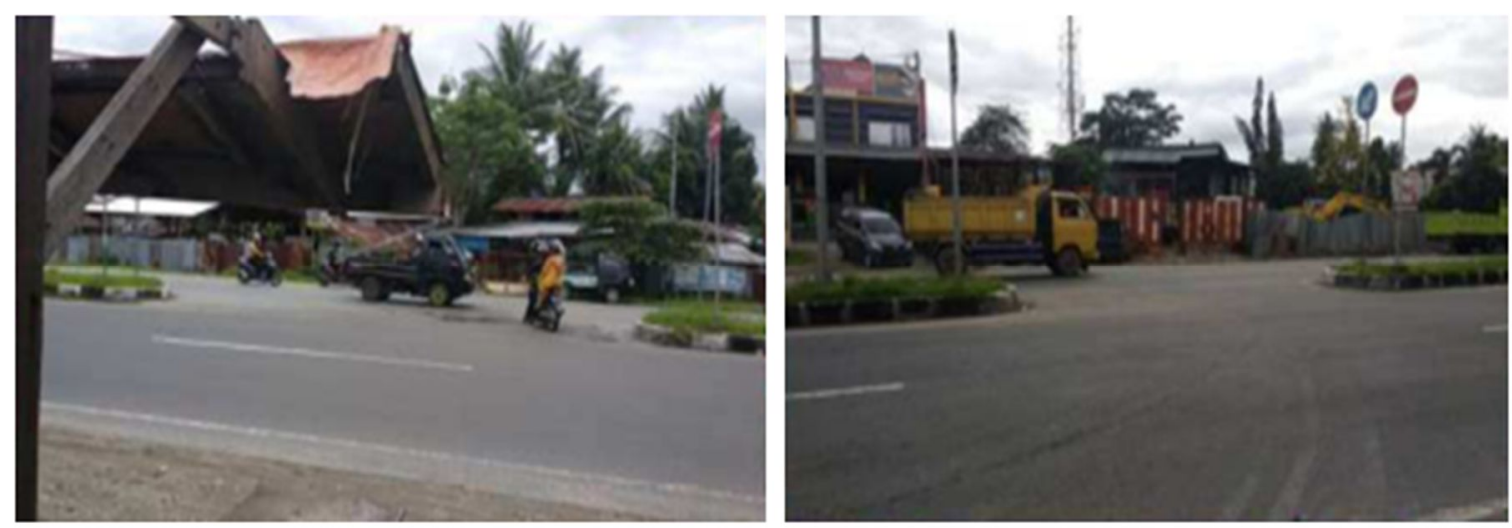

Gambar 7. Bukaan Median Sta 9+171 dan Sta 10+071

Hasil pembacaan video mendapatkan data volume kendaraan yang putar balik, volume kendaraan pada lajur paling kanan searah putar balik, serta waktu tunggu kendaraan putar balik. Data volume dikonversi dalam satuan mobil penumpang dan dikumulatif dalam 1 jam. Perhitungan panjang antrian menggunakan persamaan 1 dilakukan untuk periode waktu dimana volume kendaraan putar balik yang terbesar. Tabel 4 sampai Tabel 10 menunjukkan hasil pengolahan data lapangan pada ke-tujuh bukaan median yang ditinjau.

Tabel 4. Panjang Antrian Bukaan Median Sta 7+682

\begin{tabular}{llllll}
\hline Waktu & $\begin{array}{l}\text { Volume kendaraan } \\
\text { putar balik (smp/j) }\end{array}$ & $\begin{array}{l}\text { Volume kend. lajur } \\
\text { Paling Kanan Searah } \\
\text { putar balik (smp/jam) }\end{array}$ & $\begin{array}{l}\text { Waktu } \\
\text { tunggu } \\
\text { (det) }\end{array}$ & $\begin{array}{l}\text { Panjang } \\
\text { Antrian (m) }\end{array}$ \\
\hline $07.00-08.00$ & 129 & 162,6 & 12,93 & 162,16 \\
\hline $12.00-13.00$ & 132 & 191,6 & 15,95 & 204,98 \\
\hline $16.00-17.00$ & 124,9 & 149,9 & 12,86 & 156,04 \\
\hline
\end{tabular}

Tabel 5. Panjang Antrian Bukaan Median Sta 8+041

\begin{tabular}{llllll}
\hline Waktu & $\begin{array}{l}\text { Volume kendaraan } \\
\text { berputar (smp/j) }\end{array}$ & $\begin{array}{l}\text { Volume kend. lajur } \\
\text { Paling Kanan Searah } \\
\text { putar balik (smp/jam) }\end{array}$ & $\begin{array}{l}\text { Waktu } \\
\text { tunggu } \\
\text { (det) }\end{array}$ & $\begin{array}{l}\text { Panjang } \\
\text { Antrian (m) }\end{array}$ \\
\hline $07.00-08.00$ & 50 & 91,6 & 2,45 & 10,86 \\
\hline $12.00-13.00$ & 104,8 & 202,8 & 3,50 & 34,97 \\
\hline $16.00-17.00$ & 104,8 & 205,2 & 8,97 & 91,05 \\
\hline
\end{tabular}


Tabel 6. Panjang Antrian Bukaan Median Sta 8+251

\begin{tabular}{lllll}
\hline Waktu & $\begin{array}{l}\text { Volume } \\
\text { kendaraan } \\
\text { berputar (smp/j) }\end{array}$ & $\begin{array}{l}\text { Volume kend. lajur } \\
\text { Paling Kanan Searah } \\
\text { putar balik (smp/jam) }\end{array}$ & $\begin{array}{l}\text { Waktu tunggu } \\
\text { (det) }\end{array}$ & $\begin{array}{l}\text { Panjang } \\
\text { Antrian (m) }\end{array}$ \\
\hline $07.00-08.00$ & 68,4 & 139,1 & 4,44 & 28,68 \\
\hline $13.00-14.00$ & 100,2 & 179,4 & 14,03 & 136,57 \\
\hline $17.00-18.00$ & 139,6 & 176,8 & 9,32 & 126,26 \\
\hline
\end{tabular}

Tabel 7. Panjang Antrian Bukaan Median Sta 8+602

\begin{tabular}{llllll}
\hline Waktu & $\begin{array}{l}\text { Volume } \\
\text { kendaraan } \\
\text { berputar (smp/j) }\end{array}$ & $\begin{array}{l}\text { Volume kend. lajur } \\
\text { Paling Kanan Searah } \\
\text { putar balik (smp/jam) }\end{array}$ & $\begin{array}{l}\text { Waktu } \\
\text { tunggu } \\
\text { (det) }\end{array}$ & $\begin{array}{l}\text { Panjang } \\
\text { Antrian } \\
(\mathrm{m})\end{array}$ \\
\hline $07.00-08.00$ & 485,5 & 336,6 & 22,79 & 1081,35 \\
\hline $12.00-13.00$ & 404,1 & 511,8 & 19,15 & 756,61 \\
\hline $17.00-18.00$ & 770,4 & 588,3 & 15,50 & 1167,86 \\
\hline
\end{tabular}

Tabel 8. Panjang Antrian Bukaan Median Sta 9+171

\begin{tabular}{llllll}
\hline Waktu & $\begin{array}{l}\text { Volume } \\
\text { kendaraan } \\
\text { berputar }(\mathrm{smp} / \mathrm{j})\end{array}$ & $\begin{array}{l}\text { Volume kend. lajur } \\
\text { Paling Kanan Searah } \\
\text { putar balik (smp/jam) }\end{array}$ & $\begin{array}{l}\text { Waktu } \\
\text { tunggu } \\
(\mathrm{det})\end{array}$ & $\begin{array}{l}\text { Panjang } \\
\text { Antrian } \\
(\mathrm{m})\end{array}$ \\
\hline $07.00-08.00$ & 24 & 110,2 & 10,33 & 23,17 \\
\hline $13.00-14.00$ & 28,8 & 400,9 & 12,22 & 33,97 \\
\hline $17.00-18.00$ & 46,9 & 332,2 & 12,72 & 57,76 \\
\hline
\end{tabular}

Tabel 9. Panjang Antrian Bukaan Median Sta 10+071

\begin{tabular}{lllll}
\hline Waktu & $\begin{array}{l}\text { Volume } \\
\text { kendaraan } \\
\text { berputar (smp/j) }\end{array}$ & $\begin{array}{l}\text { Volume kend. lajur } \\
\text { Paling Kanan Searah } \\
\text { putar balik (smp/jam) }\end{array}$ & $\begin{array}{l}\text { Waktu } \\
\text { tunggu } \\
\text { (det) }\end{array}$ & $\begin{array}{l}\text { Panjang } \\
\text { Antrian } \\
(\mathrm{m})\end{array}$ \\
\hline $07.00-08.00$ & 105,5 & 140,5 & 13,88 & 142,17 \\
\hline $13.00-14.00$ & 147,9 & 208,9 & 13,76 & 198,09 \\
\hline $17.00-18.00$ & 176,7 & 191,8 & 13,72 & 236,20 \\
\hline
\end{tabular}

Tabel 10. Panjang Antrian Bukaan Median Sta 10+912

\begin{tabular}{llllll}
\hline Waktu & $\begin{array}{l}\text { Volume } \\
\text { kendaraan } \\
\text { berputar (smp/j) }\end{array}$ & $\begin{array}{l}\text { Volume kend. lajur } \\
\text { Paling Kanan Searah } \\
\text { putar balik (smp/jam) }\end{array}$ & $\begin{array}{l}\text { Waktu } \\
\text { tunggu } \\
(\text { det })\end{array}$ & $\begin{array}{l}\text { Panjang } \\
\text { Antrian } \\
(\mathrm{m})\end{array}$ \\
\hline $07.00-08.00$ & 130 & 183,3 & 12,66 & 160,00 \\
\hline $13.00-14.00$ & 187,1 & 307,3 & 13,26 & 242,02 \\
\hline $16.00-17.00$ & 187 & 282,7 & 13,91 & 253,66 \\
\hline
\end{tabular}

Pada sta $8+602$ terjadi waktu tunggu putar balik rata-rata terbesar yaitu 22,79 detik/kendaraan pada periode waktu pukul 07.00-08.00 WIB dan volume kendaraan putar balik terbesar yaitu $770 \mathrm{smp} / \mathrm{jam}$ pada periode waktu pukul 17.00-18.00 WIB. Akibatnya terjadi panjang antrian terbesar yaitu 1167,9 meter. Salah satu penyebab adalah panjang bukaan median yang sangat pendek yaitu 5 meter. Untuk bukaan median sta $8+602$ harus dilakukan penambahan panjang. Jika tidak memungkinkan sebiknya ditutup saja, karena jarak dengan bukaan sebelumnya juga sangat dekat yaitu $125 \mathrm{~m}$, sedangkan standar SNI 2444 jaraknya $500 \mathrm{~m}$.

Waktu tunggu putar balik rata-rata terpendek yaitu 2,45 detik/kendaraan sekaligus merupakan panjang antrian terpendek 10,9 meter pada periode waktu pukul 07.00-08.00 WIB pada sta 8+041. Panjang bukaan median sebesar 11 meter mendekati standar SNI 2444:2008 sebesar 12 meter memungkinkan hal ini terjadi disamping volume kendaraan putar balik yang kecil. 
Hasil penelitian Sumarda, dkk (2019) menunjukkan kinerja U-Turn pada saat jam puncak memiliki volume lalu lintas tertinggi sebesar $489,40 \mathrm{smp} / \mathrm{jam}$, rata-rata waktu menuver tiap jenis kendaraan yaitu sepeda motor 4,41 detik/kendaraan, kendaraan ringan 15,33 detik/kendaraan dan kendaraan berat 26,29 detik/kendaraan. Hal ini terjadi dengan panjang bukaan median $21 \mathrm{~m}$.

Evaluasi tingkat pelayanan median berdasarkan waktu tunggu putar balik pada masingmasing stationing seperti terlihat pada Tabel 11. Tingkat pelayanan $\mathrm{C}$ terjadi pada sta $7+682$ dan sta 8+602, sedangkan lima stationing dengan tingkat pelayanan B.

Tabel 11. Panjang Antrian Bukaan Median Sta 10+912

\begin{tabular}{lccc}
\hline Stationing & $\begin{array}{c}\text { Waktu tunggu } \\
\text { di antrian } \\
\text { (det/kend) }\end{array}$ & $\begin{array}{c}\text { Panjang } \\
\text { antrian (m) }\end{array}$ & $\begin{array}{c}\text { Tingkat } \\
\text { pelayanan }\end{array}$ \\
\hline $7+682$ & 15,95 & 204,98 & $\mathrm{C}$ \\
\hline $8+041$ & 8,97 & 91,05 & $\mathrm{~B}$ \\
\hline $8+251$ & 14,03 & 136,57 & $\mathrm{~B}$ \\
\hline $8+602$ & 22,79 & 1081,35 & $\mathrm{C}$ \\
\hline $9+171$ & 12,72 & 57,76 & $\mathrm{~B}$ \\
\hline $10+071$ & 13,88 & 142,17 & $\mathrm{~B}$ \\
\hline $10+912$ & 13,91 & 253,66 & $\mathrm{~B}$ \\
\hline
\end{tabular}

Mengacu pada PerMenHub RI no.96/2015, tingkat pelayanan yang diinginkan pada jalan arteri primer yaitu tingkat pelayanan sekurang-kurangnya $\mathrm{B}$, maka kinerja bukaan median pada sta $7+682$ dan sta $8+602$ harus ditingkatkan dari C menjadi B. Solusinya adalah dengan menambah panjang bukaan median pada stasioning tersebut. Terutama untuk bukaan median sta $8+602$ walaupun waktu tunggu 23 detik/kendaraan tetapi panjang antrian hampir $1 \mathrm{~km}$. Jika tidak memungkinkan menambah panjang sebaiknya ditutup.

\section{KESIMPULAN}

Hasil evaluasi geometrik median jalan By Pass pada lokasi studi disimpulkan sudah sesuai standar SNI 2444/2018, walaupun tinggi median kurang hanya $1 \mathrm{~cm}$. Hal ini dikarenakan lapis ulang (overlay) pada bagian perkerasan jalan.. Ditinjau dari panjang bukaan median, semua bukaan median dalam wilayah studi tidak memenuhi SNI 2444/2018 yaitu 12 meter. Panjang bukaan median eksisting di lapangan adalah 5-11 m. Jarak antar median pada sta 7+682, 8+041, 8+251, 8+602 yaitu 255, m, 335,1 m, 199,1 m, 125,5 m. Kondisi ini tidak memenuhi standar SNI 2444/2018 karena kurang dari $500 \mathrm{~m}$. Tiga bukaan median lainnya memenuhi syarat dengan jarak 565,4 m, $625 \mathrm{~m}$, dan $841 \mathrm{~m}$. Semua bukaan median yang ditinjau tidak memiliki pelebaran sebagaimana diatur dalam SNI 2444/2018.

Evaluasi kinerja bukaan median berdasarkan waktu tunggu putar balik adalah waktu tunggu terpanjang adalah 22,79 detik/kendaraan pada periode waktu pukul 07.00-08.00 WIB dan volume kendaraan putar balik terbesar yaitu $770 \mathrm{smp} / \mathrm{jam}$ pada periode waktu pukul 17.0018.00 WIB. Akibatnya terjadi panjang antrian terbesar yaitu 1167,9 meter. Salah satu penyebab adalah panjang bukaan median yang sangat pendek yaitu 5 meter, terjadi pada sta $8+602$. Waktu tunggu putar balik rata-rata terpendek yaitu 2,45 detik/kendaraan sekaligus merupakan panjang antrian terpendek 10,9 meter pada periode waktu pukul 07.00-08.00 WIB pada sta $8+041$.

Tingkat pelayanan $\mathrm{C}$ terjadi pada sta $7+682$ dan sta $8+602$, sedangkan lima stationing lainnya dengan tingkat pelayanan $\mathrm{B}$. Tingkat pelayanan $\mathrm{C}$ harus ditingkatkan menjadi $\mathrm{B}$ sesuai PerMenHub RI no.96/2015, yaitu dengan dengan menambah panjang bukaan 
median pada stasioning tersebut. Terutama untuk bukaan median sta $8+602$ walaupun waktu tunggu 23 detik/kendaraan tetapi panjang antrian hampir $1 \mathrm{~km}$. Jika tidak memungkinkan menambah panjang sebaiknya ditutup.

\section{UCAPAN TERIMAKASIH}

Penulis mengucapkan terima kasih atas Hibah Publikasi Fakultas Teknik Tahun Anggaran 2021.

\section{DAFTAR PUSTAKA}

Barnabas, P. L., Kasan, M., \& Lestari, S. P. (2017). Evaluasi Kelayakan Median Beberapa Ruas Jalan di Kota Palu. Journal Teknik Sipil Dan Infrastruktur, Ұ(1).

Departemen Pekerjaan Umum. (2008). Spesifikasi Bukaan Pemisah Jalur, SNI 2444:2008. Badan Standarisasi Nasional, Departemen Pekerjaan Umum.

Departemen Permukiman dan Prasarana Wilayah. (2004). Perencanaan Median Jalan, Pd. T-172004-B. Departemen Permukiman dan Prasarana Wilayah.

Direktorat Jenderal Bina Marga. (1997). Manual Kapasitas Jalan Indonesia. Direktorat Jenderal Bina Marga.

Direktorat Jenderal Bina Marga. (2005). Perencanaan putaran balik (U-turn) No: 06/BM/2005. Departemen Pekerjaan Umum Direktorat Jenderal Bina Marga.

Gultom, B., Sulistyorini, R., \& Putra, S. (2019). Pengaruh bukaan (U-Turn) di ruas Jalan ZA Pagar Alam terhadap kinerja lalu lintas (Studi kasus U-Turn di depan Wisma Bandar Lampung). Jurnal Rekayasa Sipil Dan Desain, 72), 299-310.

Menteri Perhubungan RI. (2015). Peraturan Menteri Perhubungan Republik Indonesia nomor 96 tahun 2015 tentang Pedoman Pelaksanaan Kegiatan Manajemen dan Rekayasa Lalu Lintas.

Romadhona, P. J., \& Fauzi, R. I. (2018). Analisis Dampak Gang pada Putaran Balik Terhadap Kinerja Ruas Jalan Raya Affandi Yogyakarta. Jurnal Teknologi Rekayasa, 3(1), 29-38.

Sinaga, M., \& Surbakti, M. (2017). Analisis Kapasitas Bukaan Median (U-Turn). Jurnal Teknik Sipil USU, G(1).

Sumarda, G., Kariyana, I. M., \& Saputra, D. (2019). Analisa Kinerja U-Turn Dan Ruas Jalan Di Jalan By Pass Ngurah Rai Denpasar. Jurnal Teknik Gradien, 11(1), 32-45. 